\title{
Research Article \\ Shape Optimization of the Cross-Section for Noncircular Hypersonic Missile Forebody
}

\author{
Jingfan Chen $(\mathbb{D}$, Xiaoqiang Fan $(\mathbb{D}$, Bing Xiong, and Yi Wang \\ College of Aerospace Science and Engineering, National University of Defense Technology, Changsha, Hunan 410073, China \\ Correspondence should be addressed to Xiaoqiang Fan; xiaoqiangfan@hotmail.com
}

Received 30 July 2020; Revised 8 September 2020; Accepted 18 September 2020; Published 24 October 2020

Academic Editor: Chao Yan

Copyright (c) 2020 Jingfan Chen et al. This is an open access article distributed under the Creative Commons Attribution License, which permits unrestricted use, distribution, and reproduction in any medium, provided the original work is properly cited.

\begin{abstract}
In the hypersonic regime, noncircular missiles have attracted significant attention from researchers. The paper first summarizes the development and present situation of the noncircular missiles at home and abroad. Previous research found that the cross-section shape of missiles has a direct influence on the aerodynamics performance. To find the best cross-section shape in terms of lift-dragratio, an efficient and robust shape optimization framework is developed. Class/shape function transformation (CST) method and power-law curve are introduced to complete the parametric modeling of the noncircular missile. The evolutionary algorithm has been utilized to improve the optimization efficiency. A combination of script and journal files is written to automate the CAD loft, mesh generation, and CFD simulations process. Finally, the forebody section of a missile body is chosen as an example to deliver the whole optimization steps. The optimization results show that the lift-to-drag ratio increases from 1.8 to 2.4 when the hypersonic missile forebody cruises at the design condition. The results also demonstrate that the optimized configuration has a better aerodynamic performance than the original one over a wide speed range from Mach 2 to 8 and a wide attack of angle range from 0 to 30 .
\end{abstract}

\section{Introduction}

Hypersonic weapons, which have many advantages such as fast flight speed, long-range, and good strike efficiency [1], are specifically designed to counter missile defense systems like THAAD [2]. There are two main types of hypersonic weapons: hypersonic cruise missiles and hypersonic glide vehicles [3]. Hypersonic cruise missiles work within the Earth's atmosphere and hypersonic glide vehicles will leave and reenter the Earth's atmosphere during the flight time. Therefore, designing the optimal missile with the best aerodynamics performance is of great importance.

Since the missiles are firstly used by Germany to strike London during World War II [4], the missiles have entered the arsenals of many countries during the past years. The missile with a circular cross-section body is widely used because of its simple structure and ease of manufacture, even the latest configurations in service such as Russia's Kh-47M2 [5], China's CJ-100 [6], and the US's LGM-30G Minuteman III [7]. To improve the aerodynamic performance of circular cross-section missiles, researchers all over the world have done a lot of theoretical and experimental research [8-12]. These studies found that the best hypersonic forebody configurations in terms of performance are Von Karman (based on Haack series) and $3 / 4$ power series.

But we must admit that the aerodynamic performance of the circular cross-section missile cannot meet the maneuverability or cruise requirements in some complex scenes [13]. Therefore, people proposed the concept of noncircular cross-section shape and applied it to the design of missiles. The aerodynamic property of a noncircular missile depends largely on its shape. Some numerical and experimental work related to the missile shape has been conducted to compare the aerodynamic forces and moments between the square, diamond, and elliptic cross-sectional shapes [14-17]. Priola [18] proposed a parameter called the Shape Factor $\alpha . \alpha$ quantifies the cross-sectional shape of the missile forebody. At $\alpha=0$, the shape is circular, and at $\alpha=1$, the shape is sharpcornered.

Obtaining the aerodynamic coefficients of missiles is an important step in the design procedures. In practice, the aerodynamic coefficients can be estimated using empirical 
engineering methods based on Newtonian theory [19] or incompressible potential flow like the panel method [20]. However, the viscous effects are often neglected in these studies and real flow conditions apparently beyond the range of validity of the panel method. El-Mahdy et al. [21] conducted a comparative study of computing techniques for supersonic missile aerodynamic coefficients. It is found that the CFD results are closer to the measured values in experiments, especially for drag and moment.

The primary objective of this study is to present a novel and efficient design method of noncircular missile forebody. Firstly, a parametric cross-section shape design method based on CST [22] is proposed. Meanwhile, power-law curves are also introduced as the guideline in the lofting process. Next, an efficient robust shape optimization framework is developed which combines the optimizer with Designer, CAD tools, and CFD solver as well as other necessary modules. Finally, an optimization case study of a certain missile model is given to demonstrate the proposed framework.

\section{Design Methodology}

As mentioned above, the objective of this paper is to find the noncircular missile forebody with optimal performance. If a geometry design process is to find the optimal, the geometry including curves and surfaces needs to be parametric [23]. The external geometry of a complex three-dimensional body can be regarded as a surface lofted over a series of crosssections generated by parallel cut planes and guidelines, as shown in Figure 1. Therefore, the design of the forebody geometry is determined by the cross-section shape and guidelines. A set of cross-sections curves and guidelines on the geometry are highlighted.

A design procedure based on this philosophy is listed as follows.

(1) Overall dimensions should be given: the length, the width, and the height make up the overall dimensions, which determine the size of a forebody and influence its aerodynamic performance in return. Three views of a noncircular missile forebody are given in Figure 2. $L$ is the overall length. $W$ is the width. $H$ is the height. The ratio of the length compared to its height and width can be regarded as the fineness ratios [24] in horizontal projection and vertical projection, respectively. $H / W$ can be defined as the horizontal-to-vertical ratio

(2) The cross-sectional shape needs to be parametric: class/shape function transformation (CST) method is adopted, as shown in Eq.(1). This technique has been introduced in Ref [22].

$$
\zeta(\zeta)=C_{N 2}^{N 1}(\zeta) \cdot S(\zeta)
$$

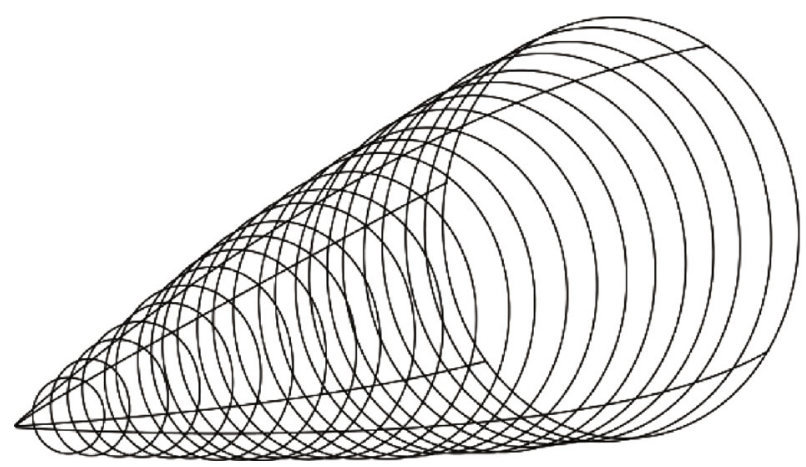

FIGURE 1: Schematic illustration of noncircular missile forebody.

In the cross-section shape design of a forebody, the shape function $S(\zeta)$ should be kept as a constant 2 . As shown in Figure 3, varying the exponents of the class function $C_{N 2}^{N 1}(\zeta)$ can provide a wide variety of cross-section shapes.

From a geometry's perspective, this is the parametric curve. But from the view of computer science, the curve is stored as many discrete points, as shown in Figure 4.

Consequently, a large number of " $x, y, z$ " coordinates are typically required to provide a mathematical or numerical description of the cross-section shape. The coordinates of section $i$ are shown in the following formula:

$$
\left\{\left(x_{i}, z_{i}^{1}, y_{i}^{1}\right),\left(x_{i}, z_{i}^{2}, y_{i}^{2}\right), \cdots,\left(x_{i}, z_{i}^{j}, y_{i}^{j}\right), \cdots,\left(x_{i}, z_{i}^{N}, y_{i}^{N}\right)\right\} \text {. }
$$

(3) Design the guidelines in the lofting process: the guide curves control the shape of the lofted surface and provide some geometric constraints. The pow-law curve is introduced to generate the guideline because of its good performance in the design of the axisymmetric forebody [9]. In this case, two guidelines are needed. Project two lines vertically and horizontally. Variations in the $x$ direction are following Eq.(3) and Eq.(4), respectively

$$
\begin{gathered}
h=\frac{H}{2}\left(\frac{x}{L}\right)^{n 1}, \\
w=\frac{W}{2}\left(\frac{x}{L}\right)^{n 2} .
\end{gathered}
$$

(4) Calculate the scaling factors: according to the geometric constraints provided by the abovementioned guideline, the overall dimension of every crosssection shape can be fixed. But there are differences between the actual and targeted coordinates of points cloud. Thus, the scaling factors should be calculated to change the size of each cross-section shape, as 

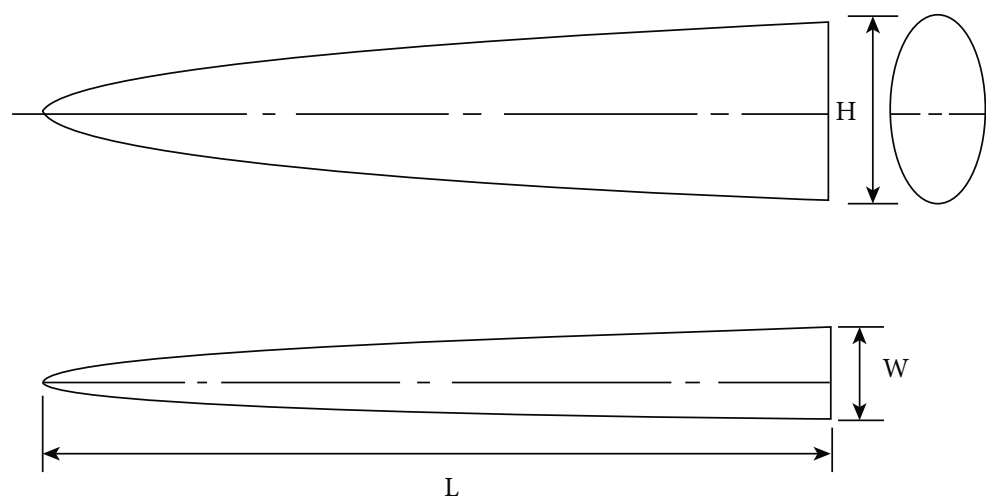

FIgURE 2: Three views of a noncircular missile forebody.
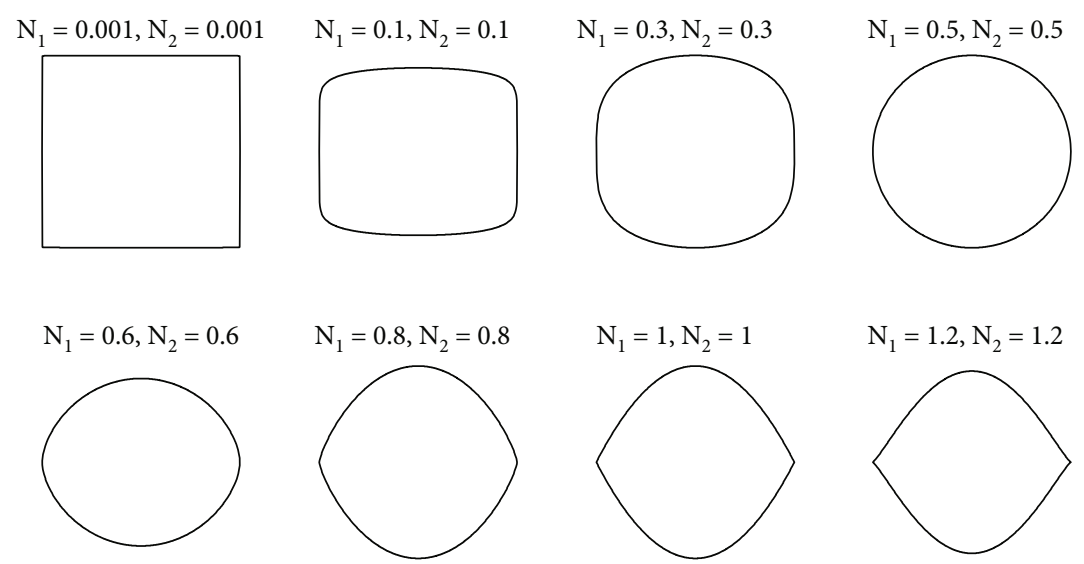

FIGURE 3: Various missile forebody cross-sectional shapes.

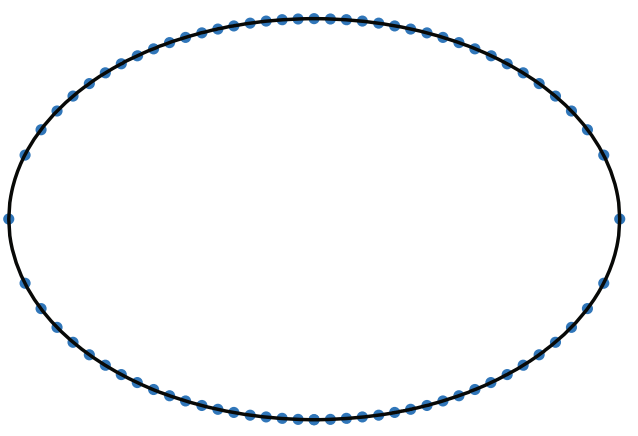

FIgURE 4: Numerical description of a curve.

shown in Figure 5. The new coordinates of targeted shape are shown in Eq.(5)

$$
\left\{\left(x_{i}, k_{i}^{y} y_{i}^{1}, k_{i}^{z} z_{i}^{1}\right),\left(x_{i}, k_{i}^{y} y_{i}^{2}, k_{i}^{z} z_{i}^{2}\right), \cdots,\left(x_{i}, k_{i}^{y} y_{i}^{j}, k_{i}^{z} z_{i}^{j}\right), \cdots,\left(x_{i}, k_{i}^{y} y_{i}^{N}, k_{i}^{z} z_{i}^{N}\right)\right\}
$$

(5) Create the 3D surface: so far, all we get are point clouds in the mathematical sense of shapes, not points, curves, and surfaces in the geometric sense. In this step, the point cloud is firstly converted into a curve with the cubic B-spline algorithm. After that, CAD software is used to stake out multiple crosssections and guidelines to obtain the smooth surface that is ultimately required.

\section{Shape Optimization Framework}

3.1. Description of the Problem. To fully define a shape optimization problem to be solved, the following basic elements must be specified exactly: (1) a basic configuration to be optimized; (2) design variables and their lower/upper bounds; (3) objective functions; (4) design constraints. These items will be described in the following paragraph.

To introduce the design method detailedly, we choose to design a simple type of missile. Its upper and lower surfaces are symmetrical. So the upper and the lower surface share a same set of N1, N2, and H. But there is no need to keep them share a same set of $\mathrm{N} 1, \mathrm{~N} 2$, and $\mathrm{H}$ if you want to design other types of vehicle. The forebody section of a certain cruise missile is selected as the base configuration. Its length is $L=3630$ $\mathrm{mm}$. The bottom section is a circle and its diameter is $1320 \mathrm{~mm}$. That means $H=1320 \mathrm{~mm}$ and $W=1320 \mathrm{~mm}$. Because the bottom section is a circle, the exponents in the class function $C_{N 1}^{N 2}(\zeta)$ are 0.5 and 0.5 . The most important 




FIgURE 5: Schematic illustration of scaling step.

TABLE. 1: The design space and initial value.

\begin{tabular}{lccc}
\hline Design parameters & $n$ & $N 1$ & $N 2$ \\
\hline Lower bound & 0 & 0.5 & 0.5 \\
Initial value & 0.5 & 0.75 & 0.75 \\
Upper bound & 1 & 1 & 1 \\
\hline
\end{tabular}

design objective function is the lift-to-drag ratio $(L / D)$. It is closely related to the maneuverability and cruise performance of the missile. When it comes to the design constraint, the curvature of the surface should be greater than 0 . For simplicity of machining and heat protection, the upper and lower surfaces of the forebody should be symmetrical. That means $n 1$ is equal to $n 2$.

Overall, the standard statement of this design optimization problem is

$$
\begin{aligned}
& \max (L / D)^{T} \\
& \text { subject to } p \in \Omega \\
& \rho \geq 0 \\
& n 1=n 2=n \\
& L=3630 \mathrm{~mm} \\
& H=1320 \mathrm{~mm} \\
& W=1320 \mathrm{~mm},
\end{aligned}
$$

where $\Omega$ is the feasible design space and $\rho$ is the surface curvature. The design space and initial value are shown in Table 1 , where $n$ is the parameter that determines the cross-section shape, and $N 1$ and $N 2$ are parameters that influence the shape of the guidelines. Several experiments have been carried out in the early stage to determine the design space. The design space should be limited to avoid the configurations that have the strange shape. These configurations may have sharp edge and suffer serious aero heating



FIgURE 6: The specific optimization process.

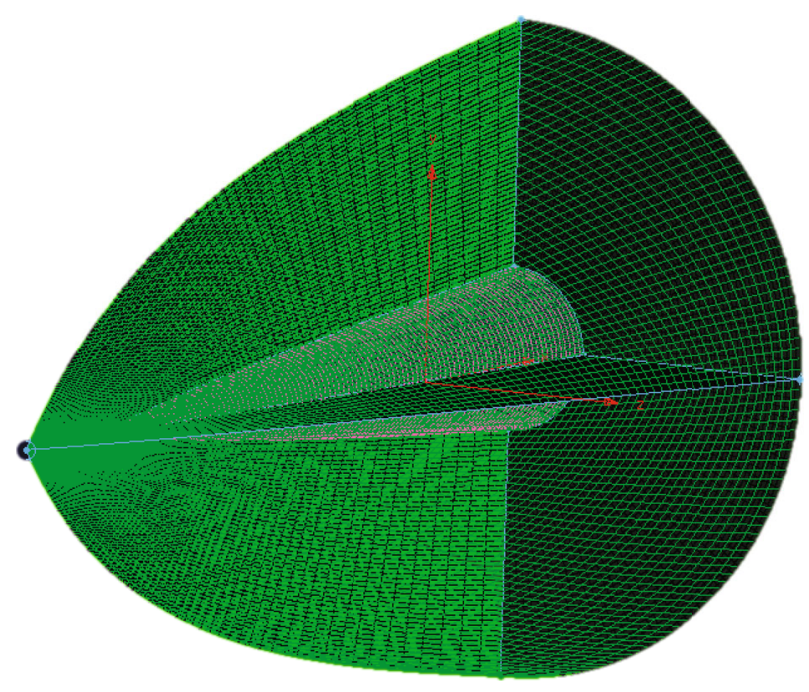

FIGURE 7: The two-block and structured mesh gird topology.

problems. In addition, these configurations may be too thin to hold enough payload.

3.2. The Optimization Processes. The optimization framework consists of the following four main parts: Designer, CAD, CFD, and Optimizer. All the abovementioned optimization components are integrated into the loop. The specific optimization process is shown in Figure 6.

3.2.1. Designer. The module has been detailedly introduced in section 2 . An efficient and flexible way to design and modify the geometry is necessary for a successful optimization process. A group of point cloud data is obtained using an in-house code based on the design methodology.

3.2.2. CAD. A capable method for geometry modeling is through the application of CAD tools. One of the easiest ways to automate a CAD process is to write a script. The script is a program that drives the CAD software with no interaction from the user. It contains a set of commandline instructions to follow. The CurveFit command is used to fit planar B-spline curves to unorganized data points. The Loft command creates a 3D surface by making a transition between two or more cross-sections. Most importantly, the geometrical objects can be saved in IGES format for meshing and CFD analysis. 


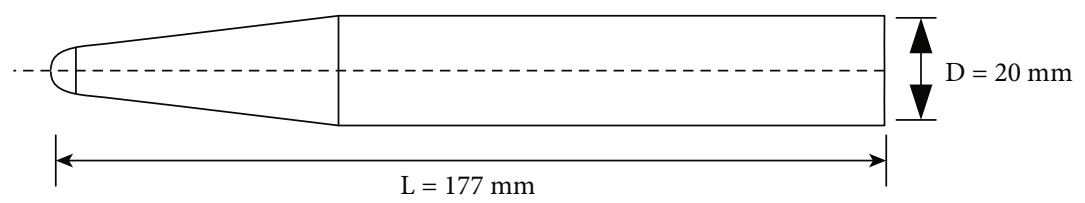

Figure 8: A sketch of the test model.

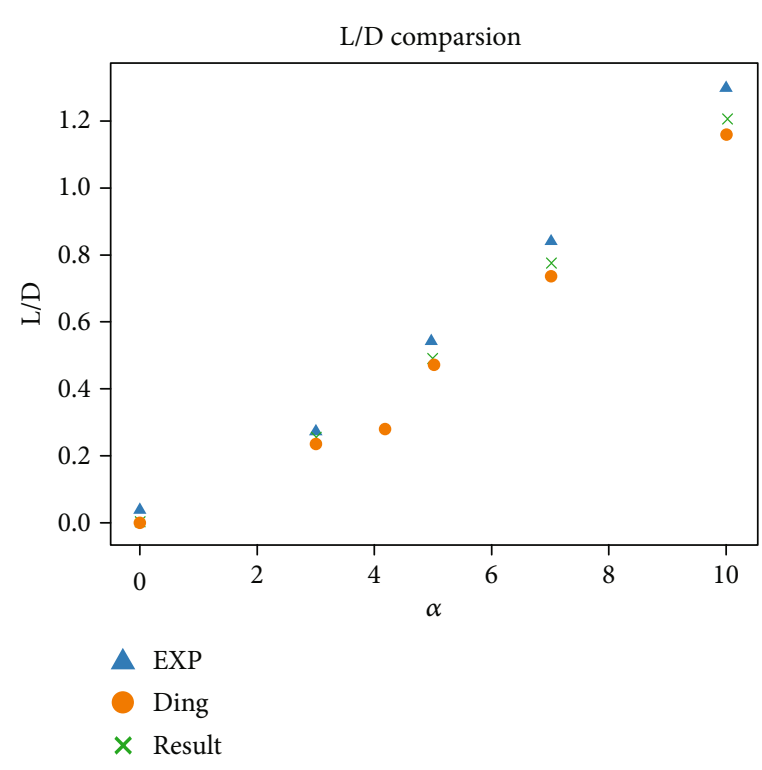

(a) $L / D$

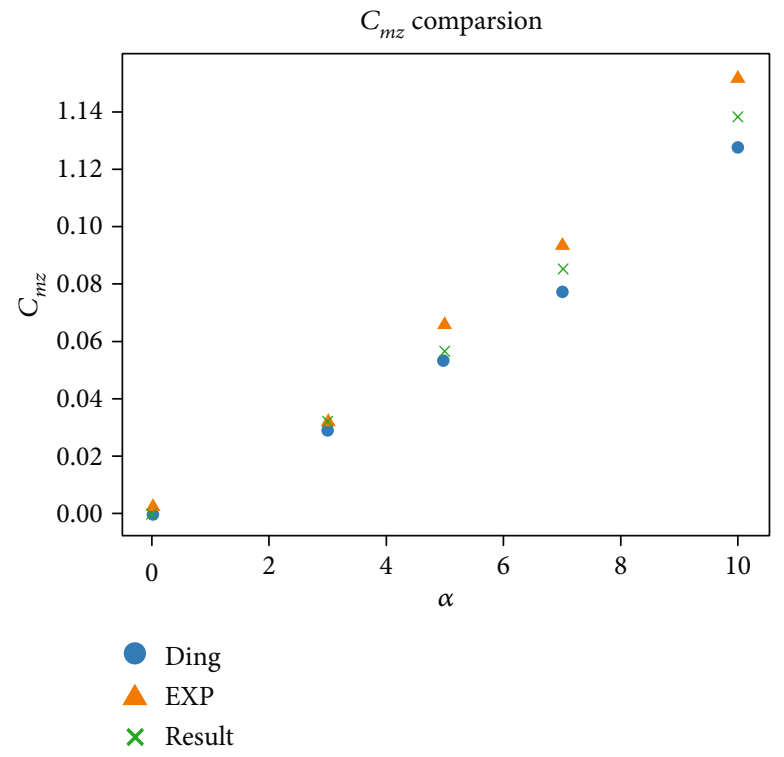

(b) $C_{m z}$

FIGURE 9: Lift-to-drag ratio and pitching moment comparison for the test model.

3.2.3. CFD. Obtaining the aerodynamic coefficients of flying vehicles such as missiles is a key step in their design process. A combination of script and journal files can automate mesh generation and CFD simulations using commercial software Pointwise and Ansys Fluent, respectively. Automatic mesh generation can guarantee the precision and stability of the numerical solution. A Glyph script is written for creating a grid for noncircular forebody within Pointwise. The topology consists of a two-block, all structured mesh designed to simulate the windward and leeward, respectively, as shown in Figure 7. The first node distance is set as $0.01 \mathrm{~mm}$ from the wall. The Reynolds Averaged Navier-Stokes (RANS) equations and the SST k-w turbulent model are adopted. The fluid is considered as ideal gas, and the wall is set as no-slip boundary condition. Solution steering capability provided with Fluent in the density-based implicit solver is used to gain convergence in a reasonable amount of time. The CFL value is adjusted by monitoring the residual history to prevent divergence and ensure the fast convergence of the solution. The flow type is hypersonic. Initial CFL value and maximum allowed CFL value are 0.5 and 10 . The value for other parameters is left to their default number. The steady conservation equations were solved until the residual levels for all variables were reduced four orders of magnitude.

3.2.4. Optimizer. To acquire a configuration with high $\mathrm{L} / \mathrm{D}$, the Evolution Algorithm is employed in this study [25]. It is well-suited for nonlinear and discontinuous design spaces. It mutates designs by adding a normally distributed random value to each design variable. The mutation strength is selfadaptive and changes during the optimization process. The algorithm has been calibrated to efficiently solve design problems with low numbers of variables and with some noise in the design space.

3.3. Computational Approach and Verification. Before relying on CFD codes to predict the aerodynamic performance of missiles with these complicated flow fields, it is important to validate the codes with reliable experimental data. To check the accuracy of the computational approach described above, a slender model is employed, as shown in Figure 8.

The aerodynamic coefficients of this model have been measured by many researchers experimentally and numerically [26]. The boundary conditions for the free stream is with the Mach number $M_{a}=8.2$, the static pressure $P_{\infty}=951.5 \mathrm{~Pa}$, and the static temperature $T_{\infty}=89.3 \mathrm{~K}$.

The angle of attack is ranging from $0^{\circ}$ to $10^{\circ}$. As shown in Figure 9, the lift-to-drag ratios calculated by the CFD method show reasonable agreement with the experimental data and Ding's results [26]. The predicted pitching moment coefficients also agree with the available numerical and experimental data. This illustrates that the numerical methods can be employed to investigate the aerodynamic performance of the hypersonic space vehicle. 




(a) $\mathrm{N1}$

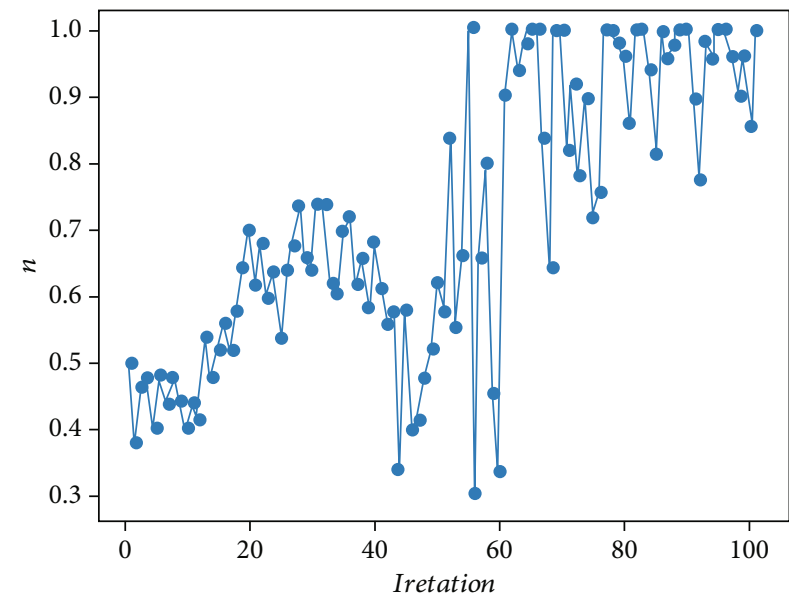

(c) $n$



(b) $\mathrm{N2}$

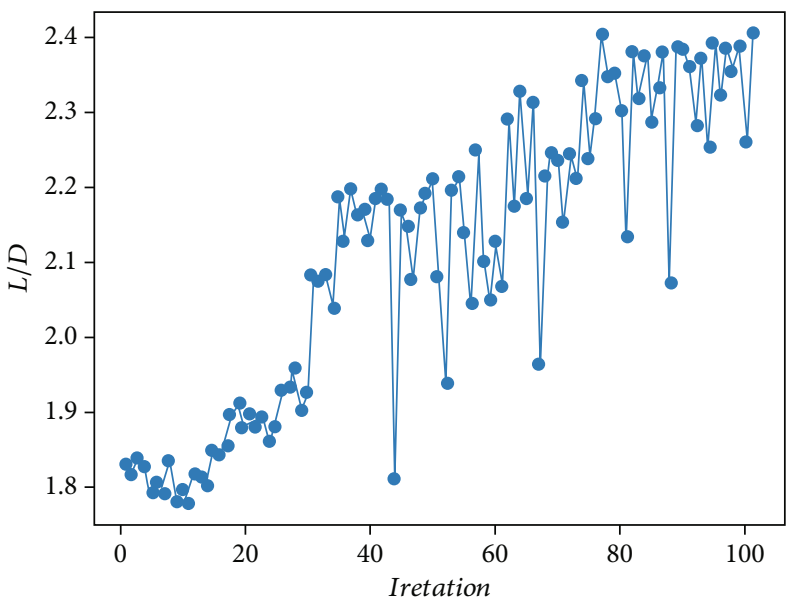

(d) $L / D$

FIgURE 10: History of iteration.
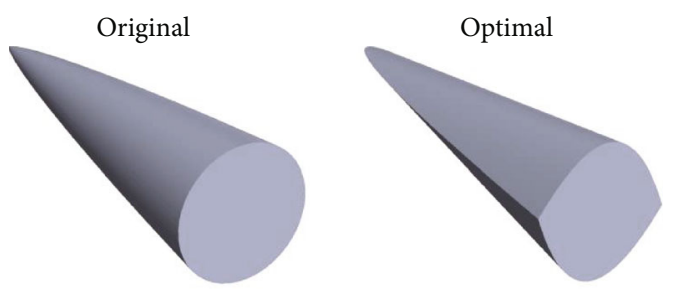

FIgURE 11: Original and optimal configurations.

\section{Results and Analysis}

4.1. Optimization Result. To test the vehicle performance under the cruise state, we selected Mach number $M=6$ and flight height $26 \mathrm{~km}$ as the design condition. The design attack of angle is 6 . Figure 10 shows the iteration history of the three design variables $(N 1, N 2, n)$ and object function (lift-dragratio $L / D$ ) in the optimizing process for the noncircular hypersonic missile forebody. Analyzing the change of three variables, it can be seen that the three variables converge to a certain fixed value. It is surprised to find all the optimal value are found at the boundaries. This means that we can
TABle 2: Difference in properties between the optimized and original configuration.

\begin{tabular}{lcccc}
\hline & $\mathrm{S} / \mathrm{m}^{2}$ & $\mathrm{~V} / \mathrm{m}^{3}$ & $\eta$ & $\mathrm{L} / \mathrm{D}$ \\
\hline Original & 8.7127 & 1.9869 & 0.8216 & 1.80 \\
Optimal & 8.4463 & 1.6867 & 0.7307 & 2.40 \\
& $-3.1 \%$ & $-15.1 \%$ & $-11.1 \%$ & $33.3 \%$ \\
\hline
\end{tabular}

use the boundary values directly when designing other similar configurations. The discovery can provide guidance for our future design work.

Figure 11 also shows comparisons between the best configuration and original configuration in terms of lift-to-drag ratio. The configuration with the maximum lift-to-drag ratio whose design parameters and property values are listed in Table 2. It is obvious that with the enhancement of lift-todrag ratio, the configuration became increasingly thinner.

In engineering design, the surface area, volume, and volumetric efficiency of the forebody are also needed to be considered. Because the ultimate purpose of the aircraft is to carry the payload. Table 2 shows the difference in volume, 

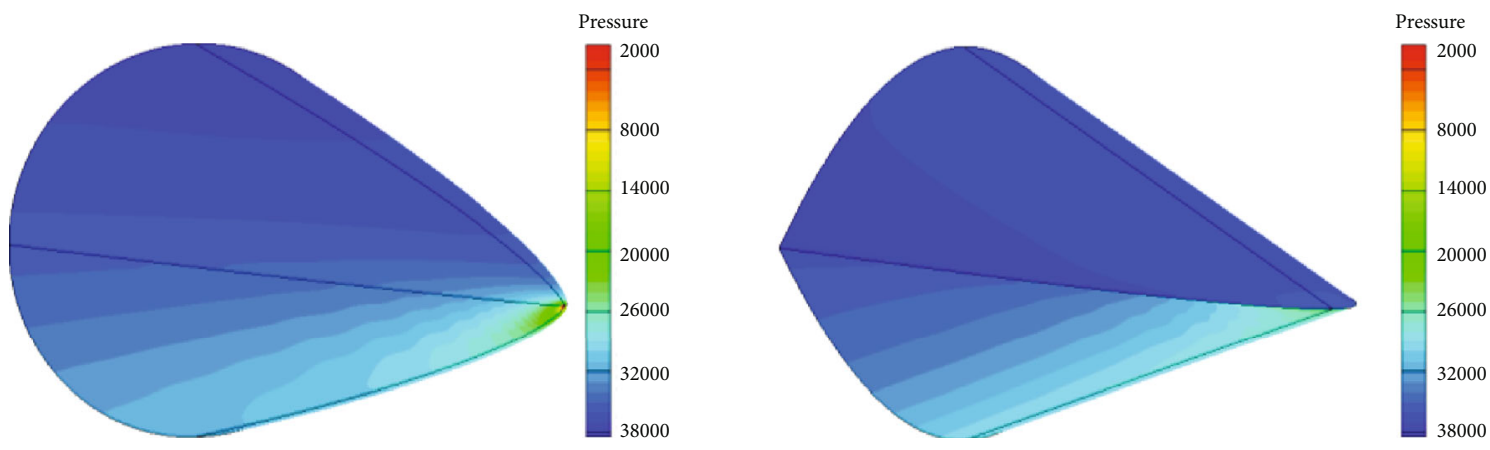

FIGURE 12: The surface static pressure distribution of the two configurations.

surface area, and volumetric efficiency between the optimized and original configuration. It can be easily found that these three indexes reduce by $3.1 \%, 15.1 \%$, and $11.1 \%$, respectively. However, it is worth noting that the lift-to-drag ratio increases by $33.3 \%$. Compared with the decrease in volumetric efficiency, the increase in the lift-to-drag ratio of the forebody is more obvious. It can be concluded that the rise in $L / D$ overwhelmed the losses in volumetric efficiency. With the increase of lift-to-drag ratio, less fuel is needed to achieve the same range. So the degree of geometric loss in the paper is acceptable.

Where the $V$ and $S$ are the inner volume and exposed surface area of the forebody, respectively.

Eq.(7) gives the definition of volumetric efficiency [16].

$$
\eta=6 \sqrt{\pi} \frac{V}{S^{3 / 2}} .
$$

4.2. Aerodynamic Performance Comparison. The surface static pressure distribution of the two configurations cruising at the angle of attack $6^{\circ}$ is illustrated in Figure 12. It is obvious that the pressure under the lower surface is higher than the pressure above the upper surface. Therefore, it can be concluded that the lift force, as well as the drag force, is generated mostly by the lower surface. Besides, the pressure at the tip of the original configuration is higher than that of optimal configuration. In turn, this also means that the former has a higher flow resistance.

Figure 13 shows the lift-to-drag ratio versus angle of attack. The angle of attack varies from $0^{\circ}$ to $30^{\circ}$. The lift-to-drag ratio increases firstly with the increase of the angle of attack and decreases subsequently with the further increase of the angle of attack when the angle of attack is larger than $9^{\circ}$. There exists an optimal angle of attack for the aerodynamic performance of the noncircular forebody, and its value is $9^{\circ}$.

Since some missions will include a speed range from low supersonic to hypersonic Mach numbers, the effect of the Mach number should be investigated. In this study, the Mach number range is 2 to 8 . The flight angle of attack is fixed at 6 degrees. For both configurations, increasing the Mach number results in large increases in the lift-to-drag ratio. Another important phenomenon obtained from Figure 14 is that the optimal configuration has better aerodynamic performance

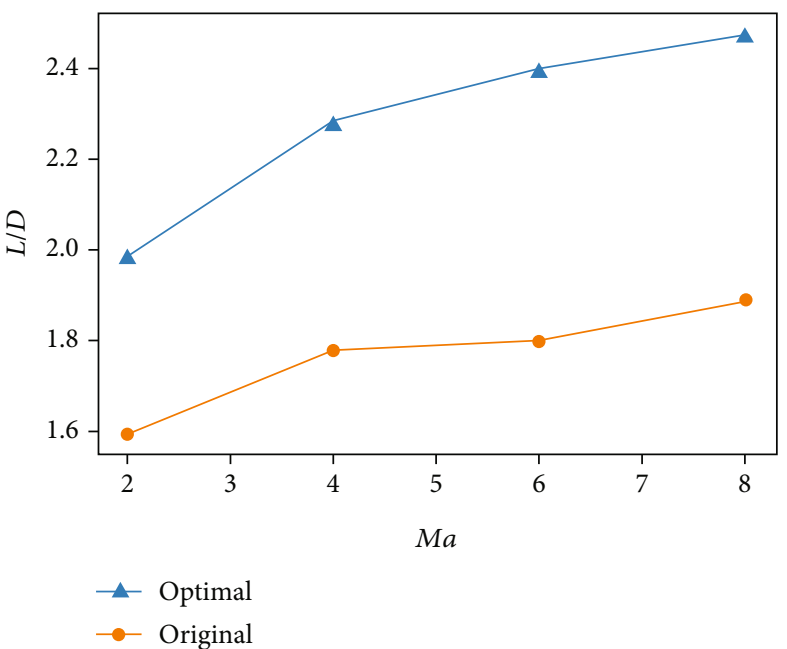

Figure 13: The lift-to-drag ratio versus angle of attack.



Figure 14: The lift-to-drag ratio verse Mach number.

than the original over a wide speed range from 2 to 8 . This property is similar to the hypersonic waverider vehicles. But waverider design is a relatively complex task. The overall design procedure of a waverider involves designing and solving of the basic flow field, tracing of a group of streamlines in the basic flow field, and lofting of all the streamlines to obtain 
the compression-stream surface of the vehicle. But when it comes to the parametric design method proposed in this paper, only a small number of parameters are needed and the three-dimensional surface can be created automatically by introducing the CST method, power-law curve, and evolutionary algorithm.

\section{Conclusion}

In this paper, a novel parametric design methodology has been developed for noncircular missile forebody design. And the optimization of noncircular missile forebody is carried out. By analyzing optimizing results and comparing the aerodynamic performance between the base configuration and optimized configuration, conclusions could be drawn as follows.

(1) A noncircular missile forebody can be parameterized and optimized by introducing the CST method, power-law curve, and evolutionary algorithm. CST method and power-law curve can define the geometrical shapes by a small number of parameters

(2) The aerodynamic characteristic of the optimal configuration could meet the requirements for a wide angle of attack and speed range including low supersonic and hypersonic speeds, which is similar to the hypersonic waverider. But this parametric design method through optimization is simpler and more efficient compared with the traditional waverider design method

(3) As an attempt to develop a shape optimization framework, only aerodynamics performance optimization has been conducted in this paper. While other important factors are not taken into account in the present work, such as aeroheating, volumetric efficiency, and structural integrity. A multidisciplinary optimization (MDO) problem can be carried out in future work

\section{Data Availability}

The data used to support the findings of this study are included within the article.

\section{Conflicts of Interest}

The authors declare that there is no conflict of interest regarding the publication of this paper.

\section{Acknowledgments}

The authors would like to express their thanks for the support from the National Natural Science Foundation of China (No. 11872071).

\section{References}

[1] W. Zhang, J. Liu, F. Ding, and W. Huang, Novel integration methodology for an inward turning waverider forebody/inlet, vol. 20, no. 12, 2019Journal of Zhejiang University-Science A, 2019.

[2] H. Yingbo and Q. Yong, "THAAD-like high altitude theater missile defense: strategic defense capability and certain countermeasures analysis," Science \& Global Security, vol. 11, no. 2-3, pp. 151-202, 2003.

[3] J. M. Acton, "Hypersonic boost-glide weapons," Science \& Global Security, vol. 23, no. 3, pp. 191-219, 2015.

[4] D. Hafemeister and D. Hafemeister, "The Offense: Missiles and War Games," in Physics of Societal Issues, pp. 43-76, Springer New York, New York, NY, 2014.

[5] H. M. Kristensen and M. Korda, "Russian nuclear forces, 2019," Bulletin of the Atomic Scientists, vol. 75, no. 2, pp. 7384, 2019.

[6] C. Chuanren, "The people's liberation army turns 70: a technologically revolutionary parade," Asia-Pacific Defence Reporter (2002), vol. 45, no. 9, pp. 40-43, 2019.

[7] O. I. Sukharevsky, G. S. Zalevsky, S. V. Nechitaylo, and I. O. Sukharevsky, "Simulation of scattering characteristics of aerial resonant-size objects in the vhf band," Radioelectronics and Communications Systems, vol. 53, no. 4, pp. 213-218, 2010.

[8] W. H. Mason and J. Lee, "Minimum-drag axisymmetric bodies in the supersonic/hypersonic flow regimes," Journal of Spacecraft and Rockets, vol. 31, no. 3, pp. 406-413, 1994.

[9] J. Chen, X. Fan, B. Xiong, Z. Meng, and Y. Wang, "Parameterization and optimization for the axisymmetric forebody of hypersonic vehicle," Acta Astronautica, vol. 167, pp. 239244, 2020.

[10] A. Narayan, S. Narayanan, and R. Kumar, "Hypersonic flow past nose cones of different geometries: a comparative study," Simulation, vol. 94, no. 8, pp. 665-680, 2018.

[11] N. R. Deepak, T. Ray, and R. R. Boyce, "Evolutionary algorithm shape optimization of a hypersonic flight experiment nose cone," Journal of Spacecraft and Rockets, vol. 45, no. 3, pp. 428-437, 2008.

[12] M. R. FINK, "Hypersonic minimum-drag slender bodies of revolution,” AIAA Journal, vol. 4, no. 10, pp. 1717-1724, 1966.

[13] X. Yan, S. Lyu, and S. Tang, "Analysis of optimal initial glide conditions for hypersonic glide vehicles," Chinese Journal of Aeronautics, vol. 27, no. 2, pp. 217-225, 2014.

[14] K. Tadakuma, Y. Tani, and S. Aso, "Effect of fuselage cross section on aerodynamic characteristics of reusable launch vehicles," Open Journal of Fluid Dynamics, vol. 6, no. 3, article 70694, pp. 222-233, 2016.

[15] F. Wilcox, T. Birch, and J. Allen, "Force, surface pressure, and flowfield measurements on a slender missile configuration with square cross-section at supersonic speeds," in 22nd Applied Aerodynamics Conference and Exhibit, Providence, Rhode Island, 2004.

[16] S. Mahjoob, M. Mani, and M. Taeibi-Rahni, "Aerodynamic performance analysis of bodies with different cross-sections," in 20th AIAA Applied Aerodynamics Conference, St. Louis, Missouri, 2002.

[17] D. C. Daniel, T. R. Yechout, and G. J. Zollars, "Experimental aerodynamic characteristics of missiles with square cross sections," Journal of Spacecraft and Rockets, vol. 19, no. 2, pp. 167-172, 1982.

[18] F. J. Priolo and A. B. Wardlaw, "Supersonic noncircular missile computations," Journal of Spacecraft and Rockets, vol. 26, no. 3, pp. 151-157, 1989. 
[19] N. C. Freeman, "On a singular point in the newtonian theory of hypersonic flow," Journal of Fluid Mechanics, vol. 8, no. 1, 1960.

[20] J. L. Hess, "Panel methods in computational fluid dynamics," Annual Review of Fluid Mechanics, vol. 22, no. 1, pp. 255274, 1990.

[21] L. A. El-Mahdy, M. Y. M. Ahmed, O. K. Mahmoud, and O. E. Abdel-Hameed, "A comparative study of prediction techniques for supersonic missile aerodynamic coefficients," Journal of Mechanical Engineering, vol. 14, no. 1, pp. 35-60, 2017.

[22] B. M. Kulfan, "Universal parametric geometry representation method," Journal of Aircraft, vol. 45, no. 1, pp. 142-158, 2008.

[23] A. Sóbester and A. I. J. Forrester, Aircraft Aerodynamic Design: Geometry and Optimization, John Wiley \& Sons, Ltd, Chichester, UK, 2014.

[24] A. Sahai, B. John, and G. Natarajan, "Effect of fineness ratio on minimum-drag shapes in hypersonic flows," Journal of Spacecraft and Rockets, vol. 51, no. 3, pp. 900-907, 2014.

[25] D. Heiss-Czedik, "An introduction to genetic algorithms," Artificial Life, vol. 3, no. 1, pp. 63-65, 1997.

[26] F. Ding, C. Shen, J. Liu, and W. Huang, "Comparison between novel waverider generated from flow past a pointed von karman ogive and conventional cone-derived waverider," Proceedings of the Institution of Mechanical Engineers, Part G: Journal of Aerospace Engineering, vol. 229, no. 14, pp. 26202633, 2015. 